\title{
Article \\ Identifying Reservoirs and Estimating Evaporation Losses in a Large Arid Inland Basin in Northwestern China
}

\author{
Qian-Qian Xia ${ }^{1,2}$, Ya-Ning Chen ${ }^{3,4, *}$, Xue-Qi Zhang ${ }^{3,4}{ }^{\oplus}$, Jian-Li Ding ${ }^{1}$ and Guang-Hui Lv ${ }^{1}$ \\ 1 College of Resources and Environment Science, Xinjiang University, Urumqi 830046, China; \\ xiaqq1030@stu.xju.edu.cn (Q.-Q.X.); watarid@xju.edu.cn (J.-L.D.); ler@xju.edu.cn (G.-H.L.) \\ 2 College of Biology and Geography, Yili Normal University, Yining 835000, China \\ 3 State Key Laboratory of Desert and Oasis Ecology, Xinjiang Institute of Ecology and Geography, \\ Chinese Academy of Sciences, Urumqi 830011, China; zhangxueqi19@mails.ucas.ac.cn \\ 4 University of Chinese Academy of Sciences, Beijing 100049, China \\ * Correspondence: chenyn@ms.xjb.ac.cn
}

check for

updates

Citation: Xia, Q.-Q.; Chen, Y.-N.; Zhang, X.-Q.; Ding, J.-L.; Lv, G.-H. Identifying Reservoirs and Estimating Evaporation Losses in a Large Arid Inland Basin in Northwestern China. Remote Sens. 2022, 14, 1105. https://doi.org/ $10.3390 /$ rs 14051105

Academic Editor: Giorgio Baiamonte

Received: 23 December 2021 Accepted: 21 February 2022 Published: 24 February 2022

Publisher's Note: MDPI stays neutral with regard to jurisdictional claims in published maps and institutional affiliations.

Copyright: (C) 2022 by the authors. Licensee MDPI, Basel, Switzerland. This article is an open access article distributed under the terms and conditions of the Creative Commons Attribution (CC BY) license (https:/ / creativecommons.org/licenses/by/ $4.0 /)$.

\begin{abstract}
Reservoirs play a vital role in agricultural irrigation, food security, and ecological protection in arid and semi-arid areas where water resources are scarce. In the Tarim Basin (TB) in northwestern China, a large number of reservoirs have been built or are being built, resulting in significant evaporation losses. However, information about the distribution, area and evaporation rate of the reservoirs in TB is limited. To contribute, we present an inventory of reservoirs and calculate their monthly surface area and evaporation rate during the study period of 1990-2019, using the TerraClimate dataset, Google Earth Engine (GEE) platform, Landtrendr algorithm, Penman method, and Landsat images. The results suggest: (1) The inventory of 167 reservoirs in TB consists of 142 existing reservoirs (built before 1990), 5 new reservoirs (mountain reservoirs, built during 1990-2019), and 20 dried-up reservoirs (plain reservoirs that went extinct during 1990-2019). (2) The reservoir types in TB are mainly plain reservoirs with an altitude of less than $1500 \mathrm{~m}$ and an area of less than $10 \mathrm{~km}^{2}$, accounting for about $88 \%$ of the total number of reservoirs. (3) The surface area of the reservoirs increased at a significant rate $(p<0.05)$ of $12.45 \mathrm{~km}^{2} / \mathrm{y}$ from $401 \mathrm{~km}^{2}$ in 1990 to $766 \mathrm{~km}^{2}$ in 2019. (4) The evaporation rate of the reservoirs increased at a slight trend of $0.004 \mathrm{~mm} / \mathrm{d} / \mathrm{a}$ and varied from $2.57 \mathrm{~mm} / \mathrm{d}$ in 1990 to $2.39 \mathrm{~mm} / \mathrm{d}$ in 2019. Lastly, (5) The evaporation losses of reservoirs in TB significantly increased $(p<0.05)$ from $4.72 \times 10^{8} \mathrm{~m}^{3}$ to $4.92 \times 10^{8} \mathrm{~m}^{3}$ due to the significant increase in reservoir surface area $(p<0.05)$ and the slight increase in evaporation rate from 1990 to 2019. This study provides essentials of the reservoir inventory, surface area, and evaporation rate with considerable baseline inferences for TB that may be beneficial for long-term investigations and assist in local water resources decision support and sustainable management in arid regions.
\end{abstract}

Keywords: Tarim Basin; reservoir surface area; reservoir evaporation rate; Google Earth Engine

\section{Introduction}

Reservoirs play an important role in agricultural production, as well as in the social economy and ecological environment. Nevertheless, the evaporation of reservoirs significantly affects the availability of the reservoirs' water supply and thus aggravates the problem of water shortages [1]. Over the past few decades, the number of global reservoirs has risen sharply. The surface area of reservoirs has also increased from $4.11 \times 10^{5} \mathrm{~km}^{2}$ in 1984 to $4.48 \times 10^{5} \mathrm{~km}^{2}$ in 2015 [2]. The increase in reservoir surface area has led to an increase in reservoir evaporation losses [3].

Evaporation is a crucial aspect of the hydrological cycle in arid and semi-arid regions. It is also a major contributor to water loss in reservoirs [4]. According to statistics, the annual evaporation losses of reservoirs in arid and semi-arid regions accounts for about $40 \%$ of reservoir volume, thus aggravating the water shortage [5]. Therefore, studying 
evaporation losses in these reservoirs is vital for scientific monitoring and optimal water resource allocation.

The reservoir evaporation volume is calculated by multiplying the reservoir surface area by the reservoir evaporation rate $[3,6,7]$. Notwithstanding the challenges in obtaining reservoir surface area and evaporation rate data, accurate surface area and evaporation rate estimations are still required to accurately quantify the evaporation volume of reservoirs. To date, reservoir surface area is generally obtained through field measurements or remote sensing images [8]. Field measurements are mainly based on the water-area curve of a reservoir [9], but this approach is time consuming and labor intensive. Furthermore, surveying in some regions with harsh natural conditions is challenging, resulting in a scarcity of accurate reservoir data. Unlike traditional field-measurement methods, remote sensing has the advantages of wide coverage, long time sequences, and easy acquisition. Particularly, Landsat products have the advantages of continuous-time coverage and high spatial resolution (30 m). Furthermore, Google Earth Engine (GEE), a cloud platform for processing Landsat products, has emerged in recent years as a good option for conducting large-scale and long-term series analysis of reservoir surface area changes [10-13]. Although the Penman method [14] can more accurately calculate evaporation through the input of a series of parameters for evaporation, meteorological data for evaporation calculations are often not recorded from reservoir surfaces. Moreover, water bodies have a heat storage effect, which means that the calculated evaporation results may not reflect real evaporation. Many studies have been conducted on these two issues [15-19]. In recent years, Zhao and Gao [6] have systematically integrated and improved the previous results to more accurately calculate water-surface evaporation. The improved results have been verified and widely used to calculate reservoir evaporation [6,7].

China, as the world's largest developing country, has developed about 98,800 reservoirs as of 2018. Only the surface area of the large reservoirs was $0.15 \times 10^{5} \mathrm{~km}^{2}$ in 2018, leading to $140.2 \times 10^{8} \mathrm{~m}^{3}$ evaporation losses [7]. The evaporation losses of medium and small reservoirs are unknown because of the scarce information (e.g., location, shape, and area). Highlighting the study area, the Tarim Basin (TB), which is the largest arid inland basin and an important grain production base in China, has built a large number of medium and small reservoirs to ensure agricultural irrigation. As TB is a typical inland arid area, the evaporation losses in reservoirs are generally large [20]. However, the existing literature on local reservoir evaporation has primarily focused on ways to reduce evaporation through technology [21]. A few studies have looked at evaporation losses in reservoirs across the basin. They focus on the evaporation of a few reservoirs, but do not carry out relevant research on the whole basin [22-24]. Acquiring and updating reservoir information and calculating the evaporation losses is therefore critically important for ensuring food security and assessment of appropriate reservoir responses to extreme climatic and hydrological events, such as floods and drought under a changing environment, bearing in mind that up-to-date and comprehensive information is also important for ensuring water security.

As contribution efforts, the following three objectives have been addressed: (1) formulating an inventory of reservoirs in TB; (2) systematically analyzing spatial and temporal variations in reservoir surface area, evaporation rate, and evaporation losses in TB (1990-2019); and (3) discussing possible reasons for changes in reservoir surface area, evaporation rate, and evaporation losses in TB during the study period.

\section{Study Area}

The Tarim Basin is the largest inland basin in China (Figure 1). It is located in the hinterland of Eurasia $\left(35^{\circ} \mathrm{N}-43^{\circ} \mathrm{N}, 74^{\circ} \mathrm{E}-90^{\circ} \mathrm{E}\right)$ and covers a total area of about $1.02 \times 10^{6} \mathrm{~km}^{2}$. The region has a typical temperate arid continental climate, which features little rain and strong evaporation. The annual precipitation in the basin is only about $51.2 \mathrm{~mm}$, while the annual evaporation is as high as $2100-3000 \mathrm{~mm}$ [25]. The arid natural environment makes the local natural ecosystem and human activities heavily depend on local river runoff [26]. The rivers in the basin originate from the surrounding mountains and mainly include the 
Kaidu-Konqi River (KKR), Yarkant rive (YER), Aksu River (AKSR), Hotan river (HTR), Weigan River (WGR), Kashgar River (KSR), Keriya River (KYR), Dina River (DNR) and Qarqan River (QQR).

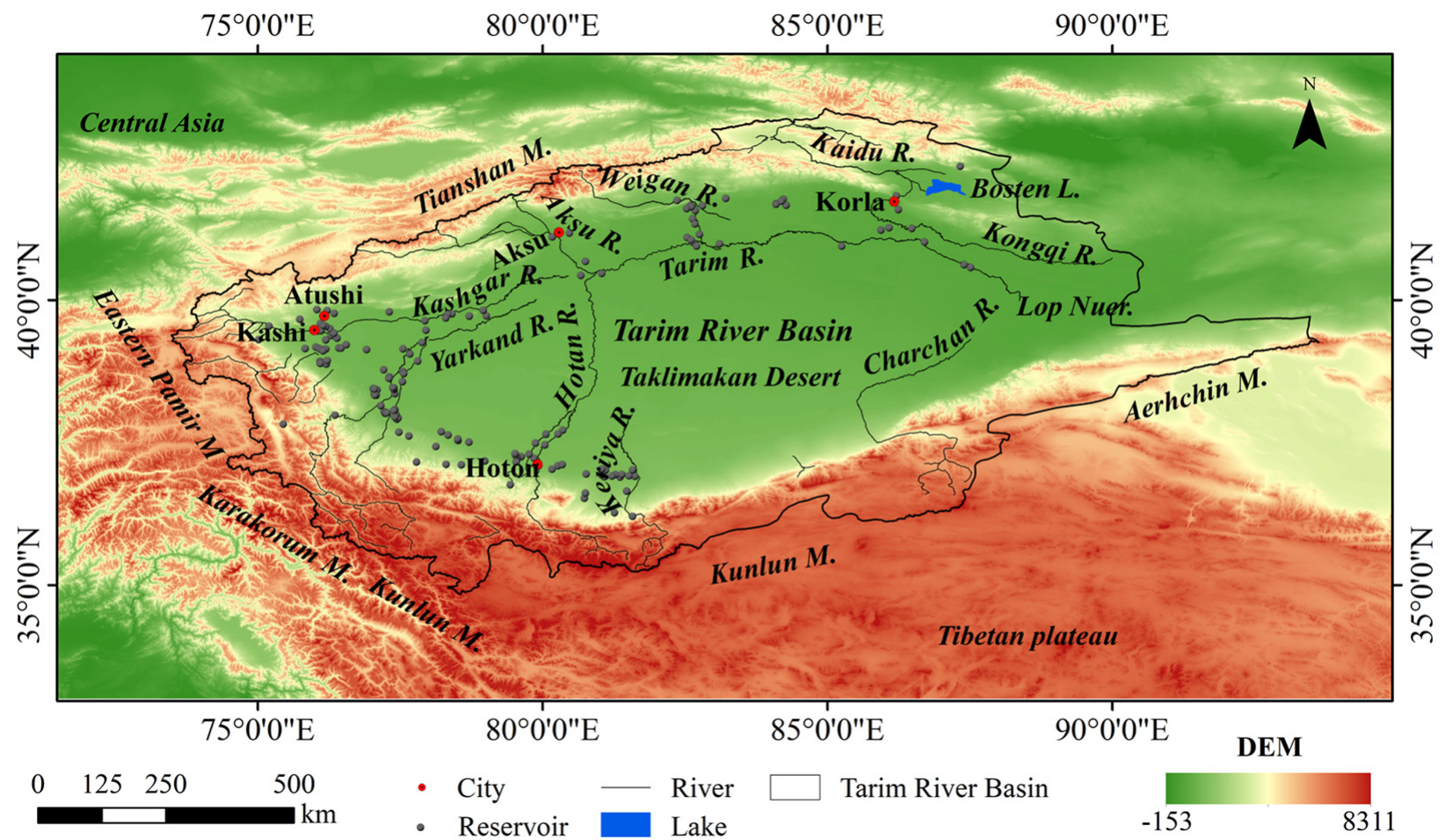

Figure 1. Description of the study area.

The rivers in TB are allogenic (exotic) rivers. The runoff from these rivers mainly comes from snowmelt and glacier-melt water (47.9\%), precipitation (27.9\%), and groundwater (24.2\%) [27]. Because snowmelt and glacier-melt water are greatly affected by temperature, the seasonal distribution of river runoff is very uneven, but approximately $75 \%$ of the annual runoff occurs from July to September. In recent years, interannual variations in river runoff increased along with global temperatures. The basin has a population of 11.6 million and 2.03 million hectares of cultivated land. Local water is mainly used for agricultural irrigation, which consumes about $96 \%$ of the total water. To make reasonable and effective use of the available water, local reservoirs have been built in TB to regulate and control water resources (Figure 1).

\section{Data and Methods}

\subsection{Data}

All Landsat (TM, ETM+, and OLI) images (49,216 scenes) covering TB from 1 January 1990 to 31 December 2019, were obtained to extract the monthly reservoir surface area. Sentinel-2 is a European wide-scan, high-resolution, multi-spectral imaging sensor, which was successfully used to evaluate the water-extraction accuracy of the reservoirs. We also referred to the Joint Research Centre Yearly Water Classification History (JRC) Global Surface Water Mapping Layers, v1.3, a dataset with high-resolution mapping results of global surface water, to generate the extent of the reservoirs. The shuttle radar topography mission digital elevation model (SRTM DEM), at a resolution of $30 \mathrm{~m}$, was used to acquire the elevation of the reservoirs.

The monthly temperature (Ta), monthly vapor pressure deficit (VPD), monthly solar shortwave radiation (SSR), and monthly wind speed at $10 \mathrm{~m}$ (U10) are calculated from the TerraClimate product (http:/ / www.climatologylab.org/terraclimate.html, accessed on 12 December 2021), a high-resolution global dataset of monthly climate and climatic water 
balance. The wind direction data were downloaded from the China Meteorological Data Service Center (https: / / data.cma.cn/, accessed on 8 December 2021). All meteorological data were used to calculate reservoir evaporation rate.

The remote sensing monitoring dataset of land use status in TB for several years (1995, $2000,2005,2010,2015)$ was used to calculate the cultivated area. The socio-economic data for TB comes from the Xinjiang Statistical Yearbook.

\subsection{Methods}

\subsubsection{Reservoir Inventory Formation}

The formation of reservoir inventory in TB includes three main steps. (1) Identifying the locations of reservoirs. To achieve this, we overlaid TB's drainage networks on Google Earth imagery and then visually identified reservoirs along with the drainage networks [28]. (2) Based on Landsat imagery, we mapped the extent of the TB's reservoirs and superimposed the position of the reservoirs with the maximum water body of JRC, making a $100 \mathrm{~m}$ buffer which was sufficient to fully study the variation in reservoir surface area in the TB during 1990-2019. (3) We identified when the reservoirs emerged and/or dried up. Landsat-based Detection of Trends in Disturbance and Recovery (Landtrendr) is a temporal segmentation algorithm to determine abrupt changes in the reservoir water. With Landtrendr method, NDWI time series with annual intervals are segmented, fitted, and smoothed to obtain the change characteristics of the NDWI value of a single pixel in the whole research period. This algorithm can effectively monitor the year, duration, and amplitude of disturbance of NDWI [29]. The utility of Google Earth historical images was explored to verify the results, after which the time of the reservoirs' generation/extinction was identified. Since the Landtrendr algorithm is calculated based on Landsat images, we only selected the period with good image quality from 1990 to 2019 in TB to identify the relevant times. Therefore, only reservoir emergence and drying up that occurred between 1990 and 2019 were identified, leaving reservoirs that were built prior to 1990 unidentified.

\subsubsection{Water Extraction and Validation}

High-quality imaging is extremely important for water extraction. The pixels for cloud, cloud shadow, and snow were removed from all the images of TB during the study period (1990-2019) using a cloud-masking method called CFmask [30,31]. All the remaining pixels were considered as effective pixels which can be used for open surface water body mapping. Images with effective pixels covering more than $70 \%$ were selected for water extraction and analysis. This process is mainly carried out in the GEE cloud platform. It has been suggested that combining the modified normalized difference water index (MNDWI), the normalized difference vegetation index $(N D V I)$ and the enhanced vegetation index $(E V I)$ is more effective at delineating than using individual indexes [32,33]. Accordingly, this study used a combination of MNDWI, NDVI, and EVI to extract surface water areas, as expressed in (Equations (1)-(3)).

To reduce specific interferences during the extraction of wetland water, the criteria of $E V I<0$ can be used to eliminate wetland vegetation interference. Therefore, the two criteria of $(M N D W I>N D V I$ and $E V I<0.1)$ and $(M N D W I>E V I$ and $E V I<0.1)$ were combined to identify the surface water bodies.

$$
\begin{gathered}
M N D W I=\frac{\rho_{\text {green }}-\rho_{\text {swir } 1}}{\rho_{\text {green }}+\rho_{\text {swir } 1}} \\
N D V I=\frac{\rho_{\text {nir }}-\rho_{\text {red }}}{\rho_{\text {nir }}+\rho_{\text {red }}} \\
E V I=2.5 \times \frac{\left(\rho_{\text {nir }}-\rho_{\text {red }}\right)}{\rho_{\text {nir }}+6 \times \rho_{\text {red }}-7.5 \times \rho_{\text {blue }}+1}
\end{gathered}
$$

where $\rho_{\text {red }}, \rho_{\text {green }}, \rho_{\text {blue }}, \rho_{\text {nir }}$, and $\rho_{\text {swir } 1}$ are the reflectance of the red band, green band, blue band, near-infrared band 1 and shortwave infrared band 1, respectively. 
The Sentinel-2A images were used to evaluate the accuracy of reservoir surface area extraction $[10,12,33]$. Considering the strong dynamical variations of reservoir surface area, the Landsat images and Sentinel images should have the same date, with a tolerance of a maximum of 2 days. A total of 20 sentinel-2A images were used. In the images, 2100 test samples-including 1055 water samples and 1055 non-water samples-were randomly generated.

The confusion matrix of water detection is presented in Table 1 . The results show that the overall accuracy and Kappa coefficients were $95.50 \%$ and 0.91 , respectively, indicating that the water information extracted based on Landsat images had high accuracy and could be used for further research.

Table 1. Confusion matrix for accuracy assessment.

\begin{tabular}{|c|c|c|c|c|c|}
\hline & \multirow{2}{*}{ Waterbody Map } & \multicolumn{2}{|c|}{ Sentinel-2 MSI } & \multirow{2}{*}{$\begin{array}{c}\text { Sum of } \\
\text { Classified Pixels }\end{array}$} & \multirow{2}{*}{$\begin{array}{c}\text { User } \\
\text { Accuracy (\%) }\end{array}$} \\
\hline & & Water & Non-water & & \\
\hline \multirow{4}{*}{ Landsat } & Water & 1005 & 50 & 1055 & $95.26 \%$ \\
\hline & Non-water & 45 & 1010 & 1055 & $95.73 \%$ \\
\hline & Sum of reference pixels & 1050 & 1060 & & $95.50 \%$ \\
\hline & Producer accuracy (\%) & $95.71 \%$ & $95.28 \%$ & & Kappa $=0.91$ \\
\hline
\end{tabular}

\subsubsection{Estimation of Reservoir Evaporation Rate}

The Penman method [14] (Equation (4)) has been widely validated for estimating open-water evaporation. In recent years, Zhao and Gao [6] systematically improved the wind function and water-heat-storage reaction of the formula to accurately calculate water surface evaporation, as follows:

$$
E=\frac{s \times\left(R_{n}-\Delta U\right)+\gamma \times f(u) \times\left(e_{s}-e_{a}\right)}{\lambda_{v} \times(s+\gamma)}
$$

where $E$ is the open water evaporation rate $\left(\mathrm{mm} \cdot \mathrm{d}^{-1}\right)$; $s$ is the slope of the saturation vapor pressure curve $\left(\mathrm{kPa} \cdot{ }^{\circ} \mathrm{C}^{-1}\right) ; R_{n}$ is the net radiation $\left(\mathrm{MJ} \cdot \mathrm{m}^{-2} \cdot \mathrm{d}^{-1}\right) ; \Delta U$ is the heat storage changes of the water body $\left(\mathrm{MJ} \cdot \mathrm{m}^{-2} \cdot \mathrm{d}^{-1}\right) ; f(u)$ is the wind function $\left(\mathrm{MJ} \cdot \mathrm{m}^{-2} \cdot \mathrm{d}^{-1} \cdot \mathrm{kPa}^{-1}\right)$; $e_{s}$ is the saturated vapor pressure at air temperature $(\mathrm{kPa}) ; e_{a}$ is the air vapor pressure $(\mathrm{kPa}) ; \lambda_{v}$ is the latent heat of vaporization $\left(\mathrm{MJ} \cdot \mathrm{kg}^{-1}\right)$; and $\gamma$ is the psychrometric constant $\left(\mathrm{kPa} \cdot{ }^{\circ} \mathrm{C}^{-1}\right)$.

The monthly evaporation volume is calculated as the product of satellite-estimated reservoir surface area and reservoir evaporation rate [3] (Equation (5)). For reservoirs that have two images per month, average values are taken, whereas for reservoirs without observation records for a given month, the reservoir surface area will supplement with the average of the preceding year and the following year.

$$
E V P=R_{\text {area }}(i, j) \times R_{\text {evp }}(i, j)
$$

where EVP is monthly reservoir evaporation volume $\left(\mathrm{m}^{3}\right) ; R_{\text {evp }}(i, j)$ is $j$ reservoir evaporation rate $(\mathrm{mm} / \mathrm{d})$ of $i$ month; and $R_{\text {area }}(i, j)$ is $i$ monthly and $j$ reservoir surface area $\left(\mathrm{km}^{2}\right)$.

\subsubsection{Trend Analysis}

Annual trends for reservoir surface area, evaporation rate, and evaporation volume were calculated using Sen's slope [34], while the significance of the trend was judged using the Mann-Kendall test [35,36].

\section{Results}

\subsection{Reservoirs in Tarim Basin}

The result of the reservoir inventory indicate that 167 reservoirs have been built in the TB, and most of these are mainly distributed in the Yarkant River Basin, the Hotan 
River Basin, the Kashgar River Basin, and Keriya River Basin (Figure 1). Further, 88\% of the reservoirs are plains reservoirs distributed at altitudes of less than $1500 \mathrm{~m}$ (Figure 1). For the entire TB, the lowest average altitude of a reservoir is located in the mainstream of the Tarim River (approx. $934 \mathrm{~m}$ ) and the highest average altitude is located in the Keriya River Basin (approx. $1581 \mathrm{~m}$ ) (Figure 1).

Using the Landtrendr algorithm, we identified abrupt changes in 25 reservoirs, including 5 newly emerging reservoirs and 20 dried-up reservoirs (Figure 2a). As examples, we took the Xiabandi Reservoir in YEB and Jiageda Reservoir in AKSB (Figure 2b-e) and verified them on Google Earth using historical images. The Landtrendr algorithm can judge the time of reservoir generation and extinction. Newly emerging reservoirs are mainly distributed at elevations of more than $2000 \mathrm{~m}$ and with areas of less than $10 \mathrm{~km}^{2}$, while the dried-up reservoirs are mainly distributed in plains regions with an elevation of less than $1500 \mathrm{~m}$ and with areas of less than $5 \mathrm{~km}^{2}$ (Figure $2 \mathrm{f}$ ).

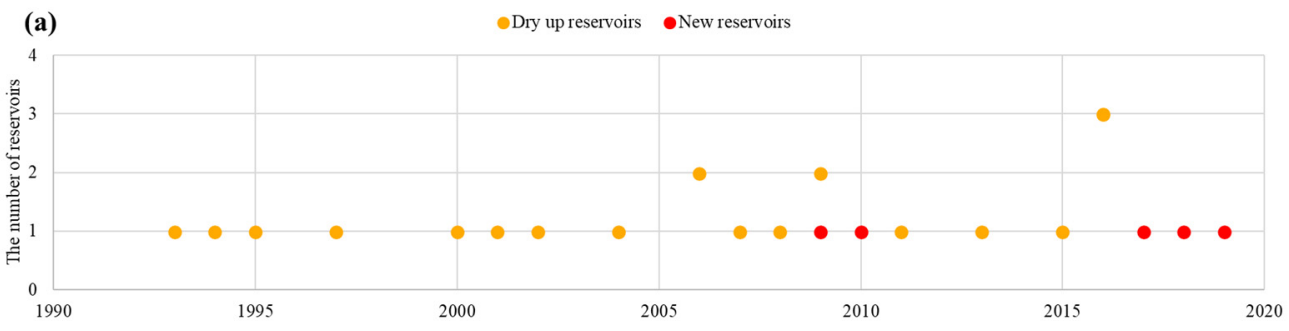

(b)

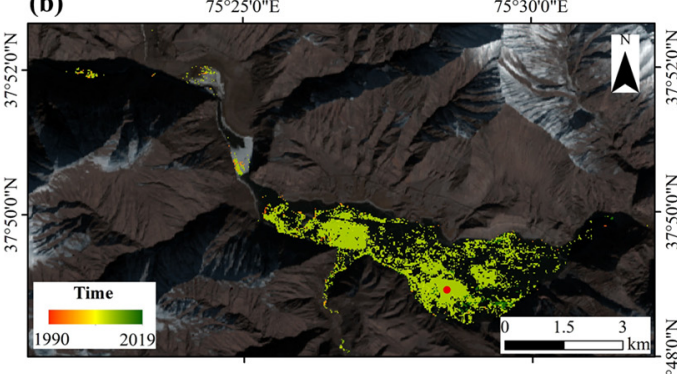

Z(d)

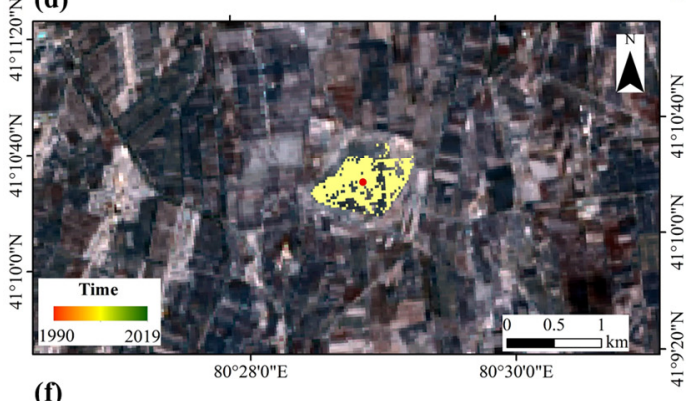

(f)

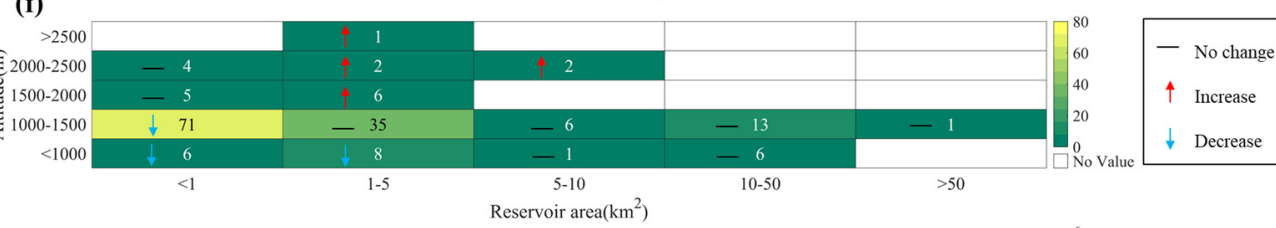

(c)

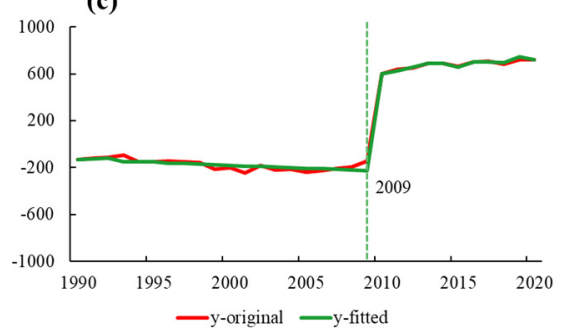

(e)

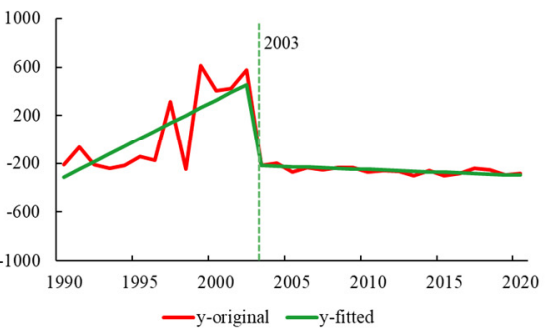

Figure 2. The evolution of reservoirs in TB (a) The number of reservoirs detected by Landtrendr algorithm; (b) change time map of water disturbance in Xiabandi Reservoir in Yarkant River Basin; (c) vertex identification map of water land conversion of Xiabandi Reservoir in Yarkant River Basin; (d) change time map of water disturbance in Jiageda Reservoir in Aksu River Basin; (e) vertex identification map of water land conversion of Jiageda Reservoir in Aksu River Basin; and (f) variation diagram of reservoir quantity distribution in TB. 


\subsection{Magnitudes and Trends of Reservoir Surface Areas}

During the 30 years of the study period (1990-2019), the total reservoir surface area in TB showed a significant increasing trend $(p<0.05)$, increasing from $401 \mathrm{~km}^{2}$ in 1990 to $766 \mathrm{~km}^{2}$ in 2019, with a growth rate of $12.45 \mathrm{~km}^{2} / \mathrm{y}$ (Figure $3 \mathrm{~b}$ ). The maximum surface area of each reservoir mainly occurs from September to March, while the minimum water area mainly occurs from April to August (Figure 3a).
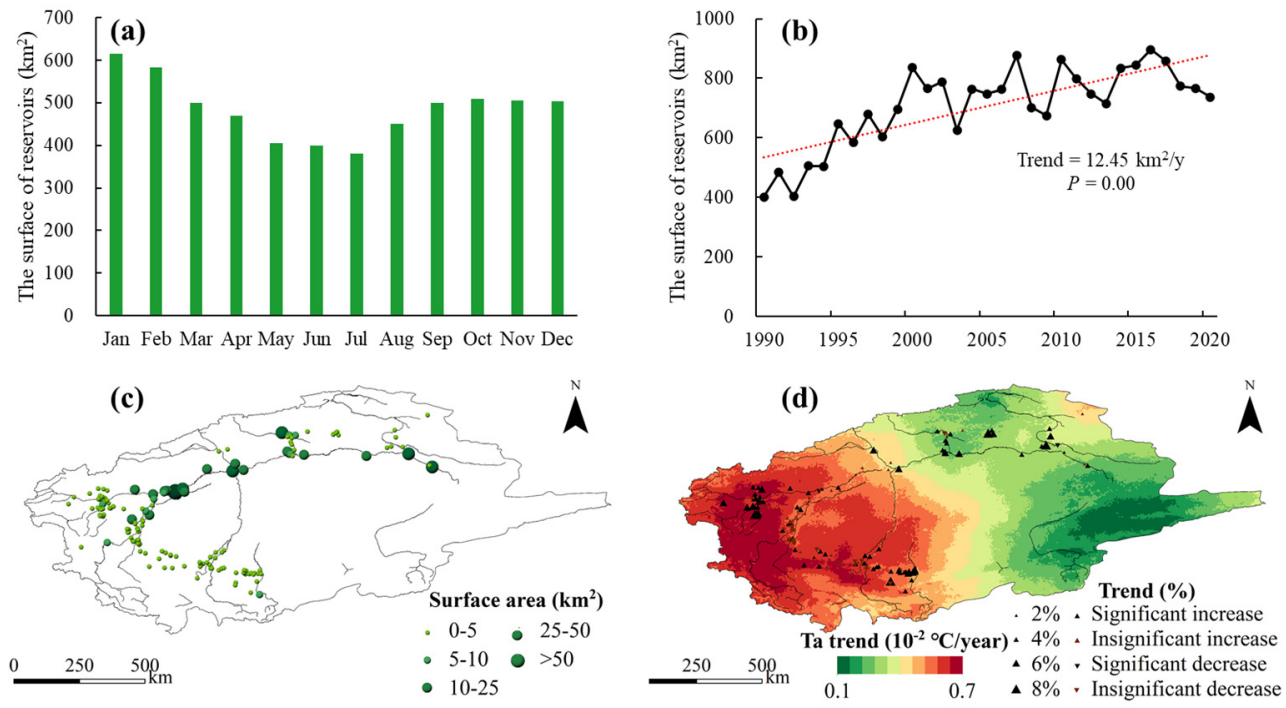

(e)

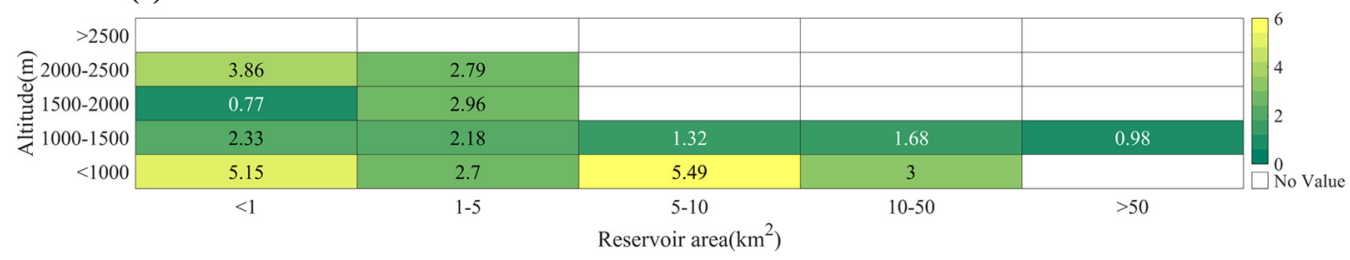

Figure 3. Reservoir area in TB from 1990-2019: (a) Annual variation in reservoir area; (b) interannual variation in reservoir area; (c) average reservoir area; (d) variation trend in reservoir area; and (e) variation trend in reservoir area at different elevations.

Among all basins in TB, the Yarkant River Basin has the largest reservoir surface area (327.85 $\mathrm{km}^{2}$ in 2019), accounting for $42.80 \%$ of TB's total reservoir surface area. The Dina River Basin has the smallest reservoir surface area $\left(4.21 \mathrm{~km}^{2}\right.$ in 2019$)$, accounting for only $0.55 \%$ of TB's total reservoir surface area (Figure $3 \mathrm{c}$ ). The reservoir surface area in the basin has a large spatial variation, ranging from $0.02 \mathrm{~km}^{2}$ to $66.48 \mathrm{~km}^{2}$. About $88 \%$ of the reservoir surface area is less than $10 \mathrm{~km}^{2}$, and about $53 \%$ of the reservoir surface area is less than $1 \mathrm{~km}^{2}$ (Figure 3c).

From 1990 to 2019, 129 reservoirs showed an increasing trend and 85 reservoirs showed a significant increasing trend $(p<0.05)$. On the other hand, 13 reservoirs showed a decreasing trend in the water area, which two of them showed a significant decreasing trend $(p<0.05)$ (Figure 3d).

Based on the analysis of the reservoirs with significant growth rates, we found that the reservoirs' surface area growth rate is higher with a lower altitude than the reservoirs with a higher altitude in the same surface-area range. For reservoirs in different surface-area range at different altitude, the reservoirs surface area growth rate is higher with the small surface area than the reservoirs with large surface area (Figure 3e).

\subsection{Magnitudes and Trends of Reservoir Evaporation Rate}

To evaluate the reliability of the Penman method for calculating the evaporation rate, the observed and modeled evaporations of eight reservoirs in TB are compared. The mod- 
eled average annual evaporations of the eight reservoirs were calculated by Equation (4), the observed average annual evaporations of the eight reservoirs were obtained through literature review [22,23]. The percent bias (PBIAS), Nash-Sutcliffe efficiency (NSE), and root-mean-square error (RMSE) returned 0.09\%, 0.89, and $19.8 \mathrm{~mm}$, respectively (Figure 4).

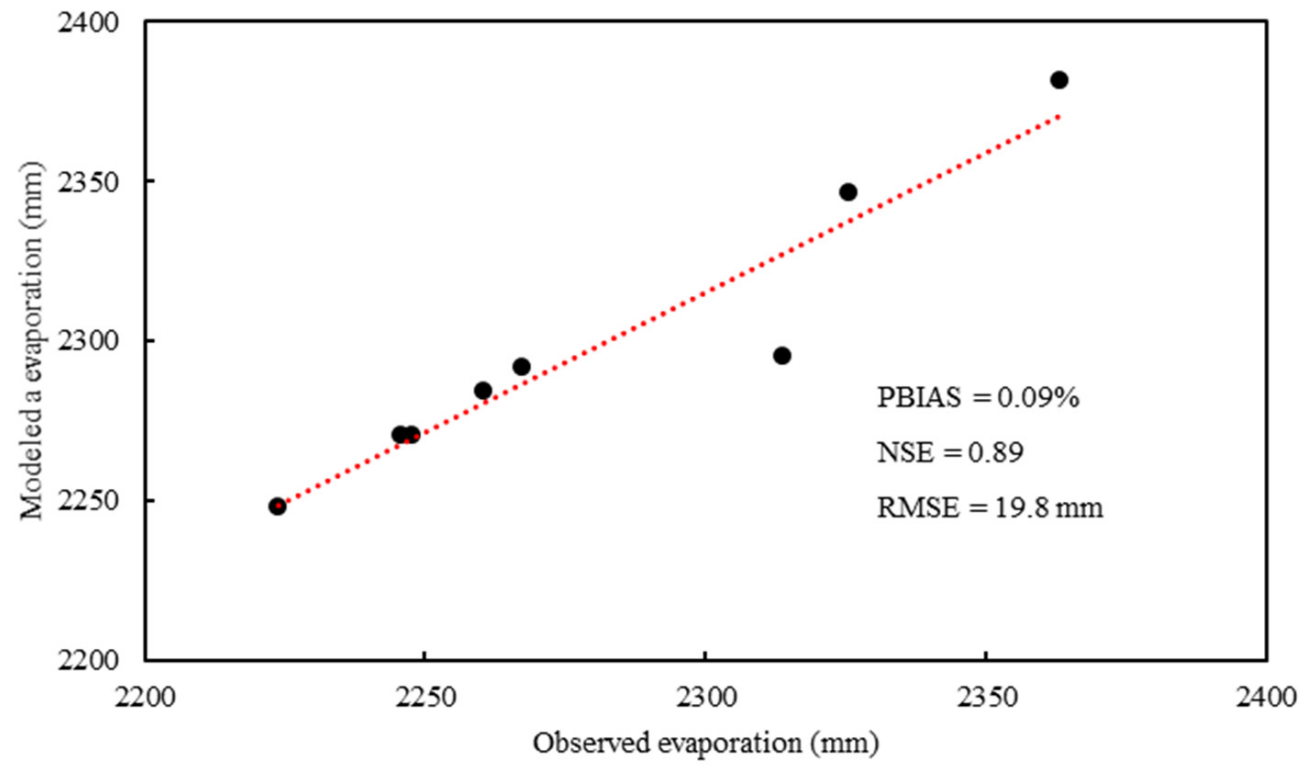

Figure 4. Observed and modeled average annual evaporation.

During the study period, the evaporation rate of reservoirs in TB showed an increasing trend at an increasing rate of $0.004 \mathrm{~mm} / \mathrm{d} / \mathrm{y}$. The maximum evaporation rate of $2.75 \mathrm{~mm} / \mathrm{d}$ occurred in 2007 and the minimum evaporation rate of $2.30 \mathrm{~mm} / \mathrm{d}$ occurred in 1993 (Figure 5a). Across the entire basin, the highest evaporation rate of $2.57 \mathrm{~mm} / \mathrm{d}$ occurred in DNB and the lowest value of $2.19 \mathrm{~mm} / \mathrm{d}$ occurred in AKSB (Figure 5b).

The spatial distribution regularity of the reservoir evaporation rate is not strong and is mainly distributed within the range of 1.54-2.93 mm/d (Figure 5c). From 1990 to 2019, the evaporation rate of 129 reservoirs showed an increasing trend, among which 44 reservoirs showed a significant increasing trend $(p<0.05)$, with an average value of $0.007 \mathrm{~mm} / \mathrm{d} / \mathrm{y}$, while 13 reservoirs showed a downward trend (Figure 5d). Reservoirs that displayed significant increases in evaporation rate $(p<0.05)$ are mainly distributed in the KSB. The increasing rate was $0.008 \mathrm{~mm} / \mathrm{d} / \mathrm{y}$.

Through the analysis of evaporation rates of reservoirs at different altitudes and different surface-area ranges, we realized that for the reservoirs with the same surface area range, the evaporation rate at low altitudes was higher than that at high altitudes. For example, in reservoirs with a surface area of less than $1 \mathrm{~km}^{2}$, the evaporation rate gradually decreased with increases in altitude, namely $2.70 \mathrm{~mm} / \mathrm{d}, 2.53 \mathrm{~mm} / \mathrm{d}, 2.39 \mathrm{~mm} / \mathrm{d}$, and $2.12 \mathrm{~mm} / \mathrm{d}$, respectively (Figure 5e). For reservoirs with different surface-area ranges, the evaporation rate of reservoirs with a small surface area was higher than that of reservoirs with a large surface area. For instance, the evaporation rate of reservoirs in the range of $1.0-1.5 \mathrm{~km}^{2}$ gradually decreased with increases in surface area, namely $2.53 \mathrm{~mm} / \mathrm{d}$, $2.41 \mathrm{~mm} / \mathrm{d}, 2.43 \mathrm{~mm} / \mathrm{d}, 2.38 \mathrm{~mm} / \mathrm{d}$, and $2.28 \mathrm{~mm} / \mathrm{d}$, respectively (Figure 5e). In addition, through analyzing changes in the reservoir evaporation rate trend, we found that although evaporation rates of reservoirs at different elevations with different surface areas showed an increasing trend, the increasing trend of small reservoirs with areas of less than $5 \mathrm{~km}^{2}$ at high altitudes is more significant (Figure 5e). 


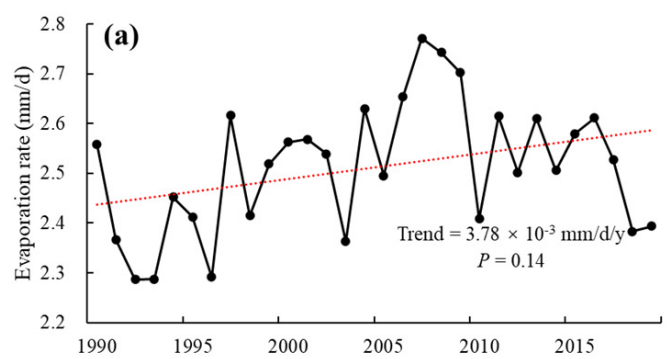

(c)

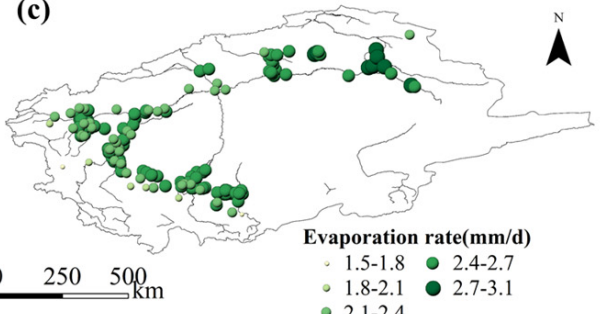

(e)

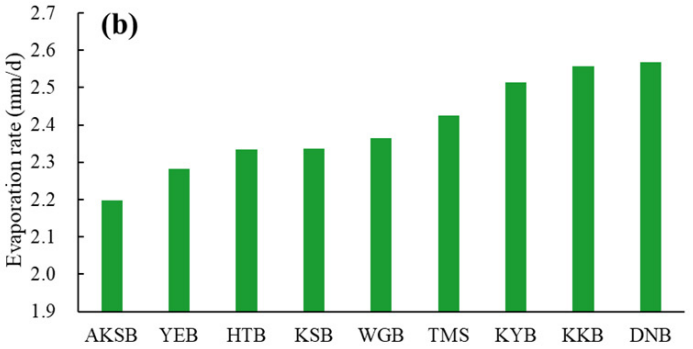

(d)
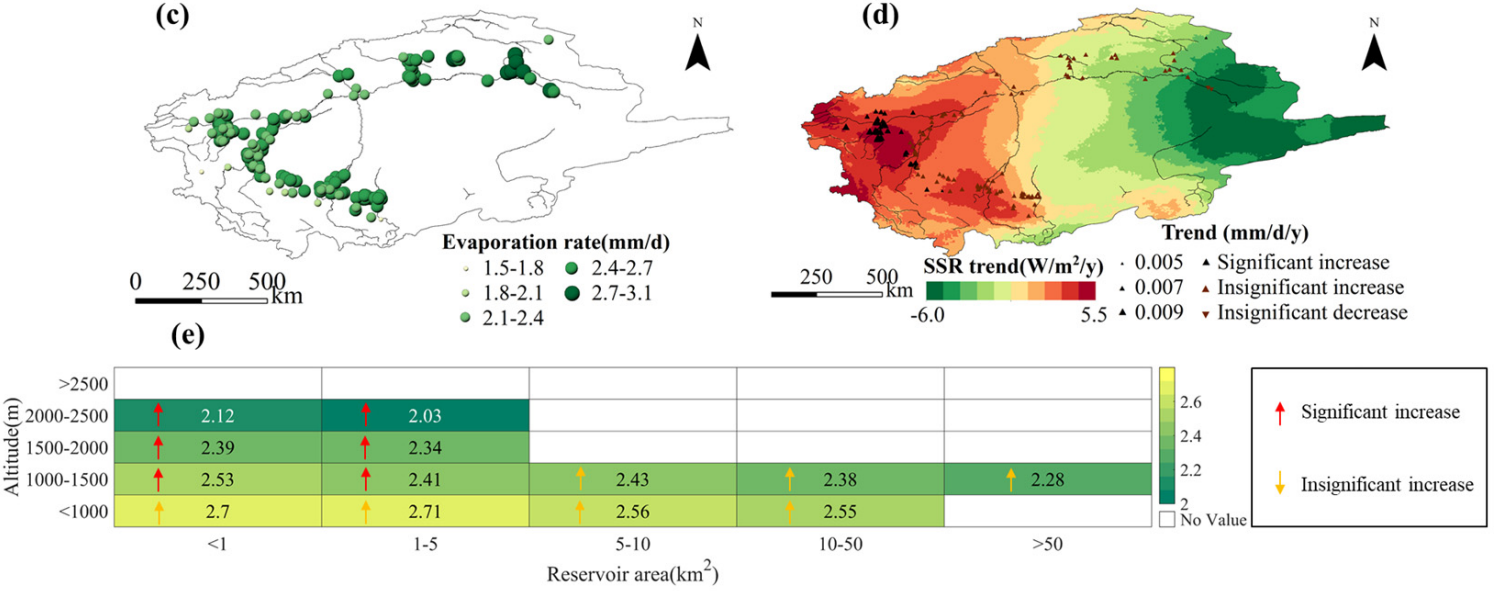

Figure 5. Evaporation rate of reservoirs in TB from 1990 to 2019: (a) Interannual variation trend of evaporation rate; (b) multi-year evaporation rates of reservoirs in each sub-basin; (c) evaporation rates of reservoirs; (d) variation trend of evaporation rate; (e) distribution and trend of evaporation rate of reservoirs at different altitudes and areas.

\subsection{Magnitudes and Trends of Reservoir Evaporation Volume}

The evaporation volume of reservoirs in TB from 1990 to 2019 showed a significant increasing trend $(p<0.05)$ due to the significant increase in reservoir surface area $(p<0.05)$ and the rising evaporation rate, increasing from $4.72 \times 10^{8} \mathrm{~m}^{3}$ in 1990 to $4.92 \times 10^{8} \mathrm{~m}^{3}$ in 2019. This represents a growth rate of $0.05 \times 10^{8} \mathrm{~m}^{3} / \mathrm{y}$ (Figure 6a).
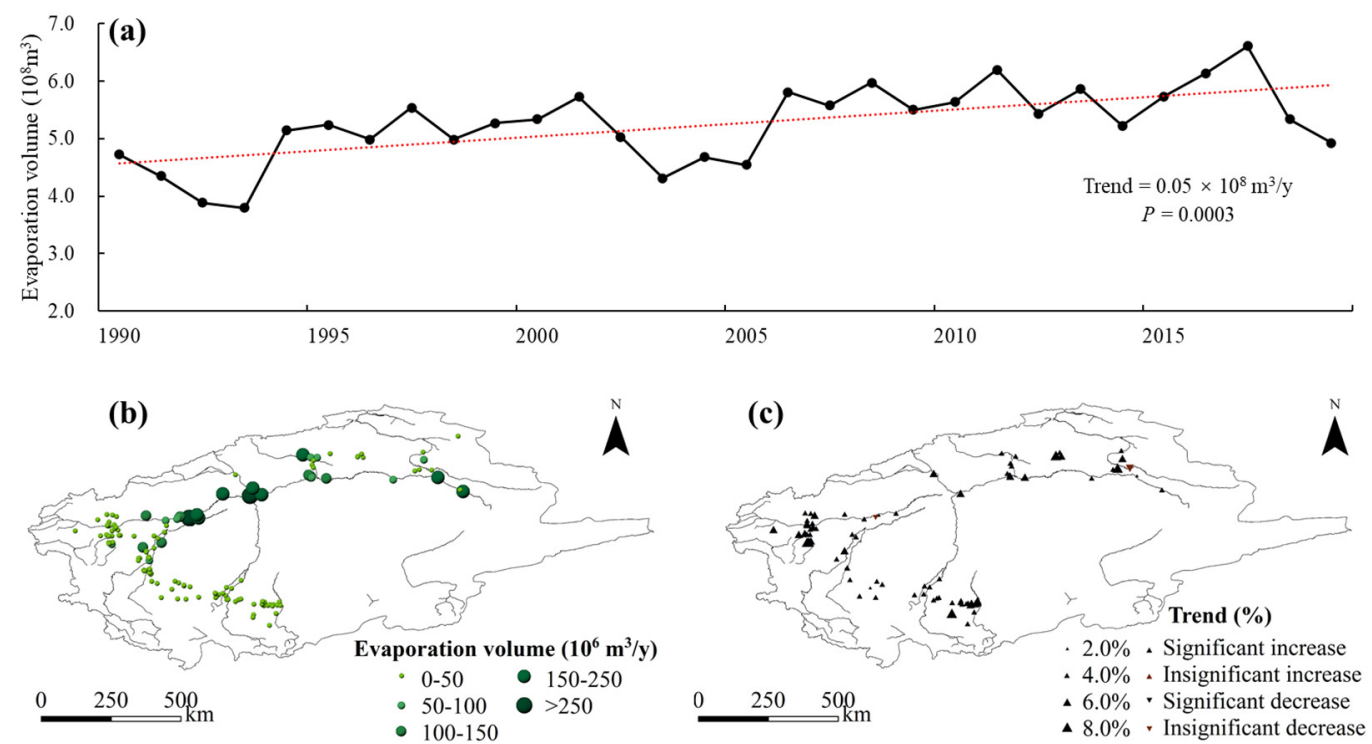

Figure 6. Evaporation losses of reservoirs in TB from 1990 to 2019: (a) Interannual variation trend of reservoir evaporation losses; (b) reservoir evaporation losses; and (c) variation trend of reservoir evaporation losses. 
The average evaporation loss of reservoirs during the study period was $5.25 \times 10^{8} \mathrm{~m}^{3}$ with the maximum evaporation volume of about $6.61 \times 10^{8} \mathrm{~m}^{3}$ occurring in 2017 . This volume represents 1.34 times the domestic water consumption and 0.84 times the ecological water consumption for the same year. Moreover, the spatial variation of perennial average evaporation losses of reservoirs in TB is large and is mainly distributed in the range of $0.02-52.13 \times 10^{6} \mathrm{~m}^{3}$ (Figure $6 \mathrm{~b}$ ). Of the 129 reservoirs that showed an increasing trend of evaporation volume, 85 showed a significant increasing trend $(p<0.05)$. Meanwhile, 13 showed a decreasing trend; of these, the evaporation volume of 2 reservoirs showed a significant decreasing trend $(p<0.05)$ (Figure 6c).

\section{Discussion}

\subsection{Analyzing the Evolution of Reservoirs}

The newly emerged reservoirs in TB are mainly mountain reservoirs built in the upper reaches of rivers, and most of them have the comprehensive task of ecological water supply, irrigation, flood control, and power generation. It is worth noting that with global warming, catastrophic extreme climatic and hydrological events such as floods and droughts will intensify in arid inland river basins, and that water security issues will become increasingly serious [37]. Building mountain reservoirs to cope with climate change is an important engineering measure to ensure local water security [38]. The reservoirs that are drying up are mainly plain reservoirs. Most reservoirs in TB were built before 1990 [39]. Due to the limitations of technology and economic factors, most reservoirs are plain reservoirs. With the extension of the service period of the reservoir, the properties of the reservoir (increased silting amount, weakened storage capacity) and the material of the dam (supersaturation of impermeable soil material, carbonation of concrete, etc.) changes, lead to a decrease in the safety degree of the reservoir and shorten the service life [40]. In addition, plain reservoirs often lead to the rise of groundwater, resulting in the salinization of farmland and pastoral areas around [41]. In the evolution process of reservoirs, some reservoirs with relatively comprehensive good conditions were selected artificially, while some reservoirs with poor conditions were abandoned. Therefore, the construction and extinction of local reservoirs are based on natural conditions as well as human selection.

Taking the reservoir as the water-supply body and the surrounding villages as the receiving water body, analysis of the relationship between these two shows that the drying up of the reservoirs was usually caused by multiple water-supply bodies serving the same receiving water body. In other words, several reservoirs were providing water to the same village at the same time (Figure 7a). However, analysis of single water supply bodies with single receiving water bodies shows that no reservoirs have dried up (Figure $7 \mathrm{~b}$ ). Since the TB is a typical arid area, when carrying out agricultural irrigation, reservoirs with sufficient water resources and convenient irrigation are preferred, while reservoirs with insufficient depth and low water quality will be abandoned and gradually transformed into bare or cultivated land (Figure 7c-h).

\subsection{Analysis of Variations in Reservoir Surface Area}

In arid and semi-arid regions, reservoirs are used to mitigate the impact of climate change on local water resources, and the reservoirs area changes with the climate change [42]. Snowmelt water and precipitation in mountainous areas comprise the main water sources for reservoirs in TB. A rise in temperature will aggravate the melting of snow and ice, causing an increase in water inflow and boosting the reservoir surface area. According to research on the correlation between the average annual maximum temperature and reservoir surface area in TB in past 30 years (Figure $3 \mathrm{~d}$ ), the correlation is as high as 0.7 , indicating that temperature is an important driving factor of increases in reservoir surface area.

By analyzing the land-use data, the area of cultivated land has been increased nearly 0.65 times with the development of local society and economy during the study period. The increase in cultivated land led to an increase in agricultural irrigation water demand [43]. 
TB is a typical oasis irrigated agricultural area, the agricultural water consumption accounts for about $96 \%$ of the total local water consumption. Reservoir in TB is mainly built to solve the irrigation problem [40]. With increases in agricultural irrigation water, the trend in reservoir surface area likewise increased. Hence, the expansion of cultivated area proved to be the main reason for expanding reservoir surface area.
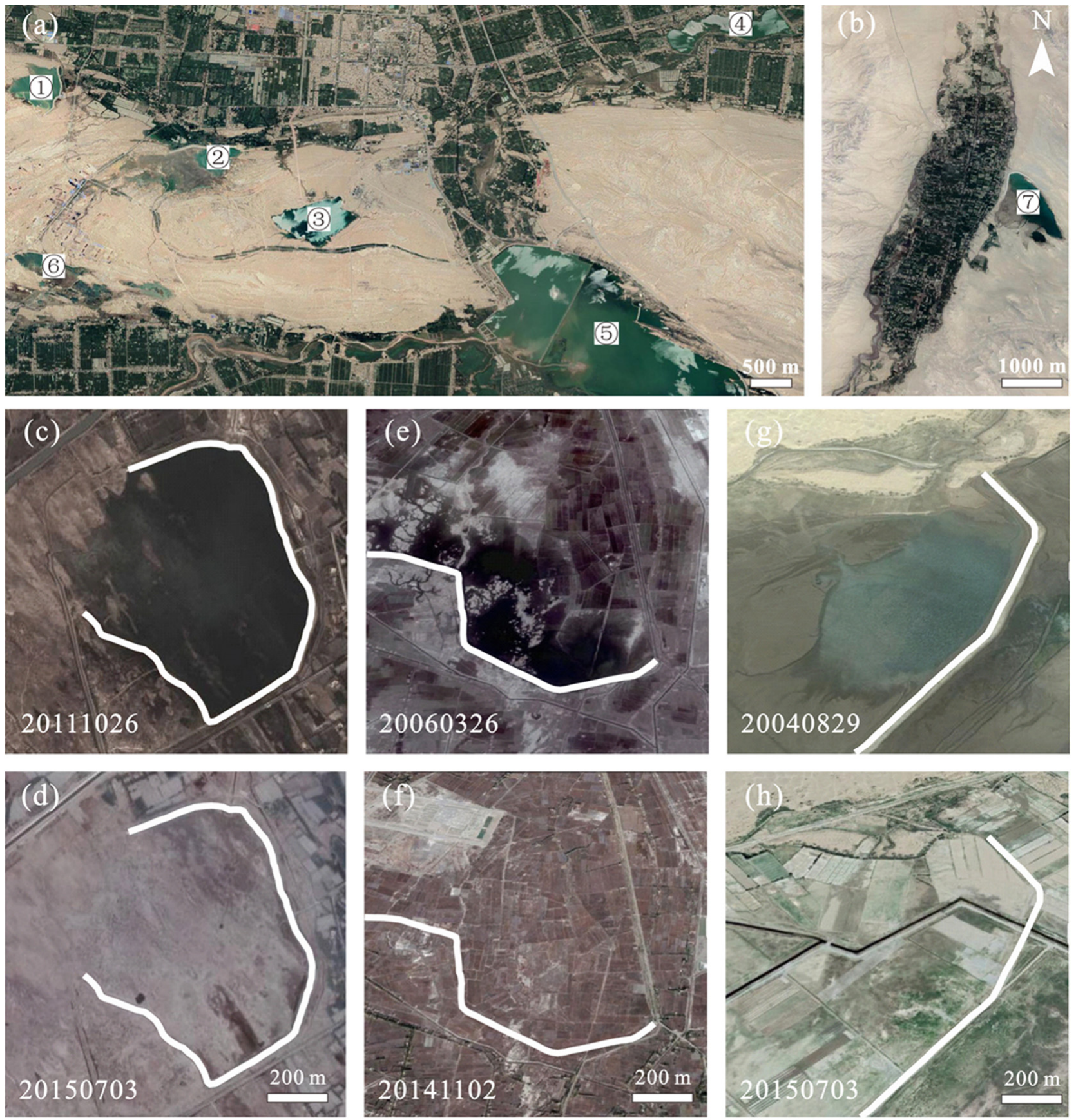

Figure 7. Example of reservoir evolution in TB from 1990 to 2019 (image from Google Earth): (a) Multiple water supply bodies serving a single receiving water body; (b) single water supply serving a single water body; (c,d) Paikeqi Reservoir in the Yarkant River Basin; (e,f) Minbing Reser-voir in the Weigan River Basin; and (g,h) Jinxing Reservoir in Hotan River Basin.

The obvious annual distribution characteristics of reservoir areas in the basin are also related to local farmland irrigation. According to local farmers, irrigation in TB generally runs from May to the end of August, which is consistent with the maximum water area 
occurrence in the reservoirs. In addition to the increase in cultivated land area, some human activities such as ecological water diversion also play an indispensable role in the reservoir surface area increment within the basin [44]. For example, the ecological water conveyance to the lower reaches of the Tarim River started in 2000 and had accumulated $84.45 \times 10^{8} \mathrm{~m}^{3}$ by the end of 2020, resulting in a significant increase in the reservoir surface area of the main stream of the Tarim.

\subsection{Analysis of Evaporation Rate Change of Reservoir}

By analyzing long-term variation trends for the main factors affecting evaporation rates, including shortwave radiation, vapor-pressure deficit, wind speed and air temperature, we found that the long-term variation trend of solar shortwave radiation is consistent with the reservoir evaporation rate (Figure 5d) and its correlation coefficient is as high as 0.93. This indicates that shortwave radiation plays a leading role in changes in reservoir evaporation rates. Therefore, the significant increase in the evaporation rate of reservoirs in the KSB is mainly caused by the continuous increase in shortwave radiation in the region. Still, the long-term correlation between the vapor pressure deficit and the evaporation rate of the reservoir is 0.84 , indicating that the saturated vapor pressure deficit is also an important factor affecting the evaporation rate of the reservoir in TB. However, wind speed and air temperature have little effect on evaporation rate. This is consistent with the conclusion regarding dominant factors affecting the evaporation rate of large reservoirs in China [7].

The altitude and area of the reservoir are also important factors affecting the evaporation rate. Looking at the evaporation rate distribution for reservoirs at different altitudes, the rate at high altitudes is lower compared to low altitudes. For instance, Aksu River Basin (AKSB) and Dina River Basin (DNB) are almost at the same altitude, and the AKSB is located in an area of intense solar shortwave radiation and sizeable saturated vapor pressure deficit. However, due to some large surface area plains reservoirs such as the Shangyou reservoir, the Shengli reservoir, and the Duolang reservoir in AKSB, the AKSB region has the lowest evaporation rate for all TB. Similarly, although DNB is located in an area with relatively weak solar shortwave radiation, it has the highest reservoir evaporation rate in TB due to the small reservoir surface area of its region.

\subsection{Influence of Reservoir Evaporation Losses on Water Resources Management}

Calculating reservoir evaporation volume is a useful reference value for the optimal management of water resources in arid and semi-arid regions. First, the calculation of evaporation helps to take appropriate measurements to reduce evaporation. In arid and semi-arid areas, the chemical covering method and floating material covering method are usually adopted to reduce evaporation losses of reservoirs [45,46]. Furthermore, accurate calculation of evaporation losses from reservoirs helps to estimate water-saving efficiency and provides scientific guidance for taking effective measures to reduce evaporation losses.

Secondly, the calculation of evaporation is helpful to adjust the operation rules of reservoirs against the background of climate change. Ignoring the evaporation losses of reservoirs may lead to an overestimation of the water available in the reservoir and thus an underestimation of the water required. Therefore, reservoir managers need to adjust the storage capacity according to evaporation losses. The Tarim Basin has a fragile ecological environment and is perpetually short of water resources. In recent years, with global warming, along with the development of the local social economy and the increase in population, the demand for fresh water resources is increasing. This has led to a series of ecological and hydrological problems, such as riparian forest degradation, river depletion, etc. Through the calculation of evaporation losses of reservoirs, effective measures can be taken to reduce evaporation and improve the utilization rate of water resources. The saved water resources may contribute to the better functioning of local social-economic development and ecological environment restoration. 


\section{Conclusions}

In this paper, the GEE cloud platform, Landtrendr algorithm, and improved Penman method were used to catalog reservoirs in TB. Additionally, the surface area, evaporation rate, and evaporation losses of reservoirs in the basin were calculated for the study period (1990 to 2019). The results revealed that:

There are 167 reservoirs in TB, consisting of 142 existing reservoirs (built before 1990), 5 new reservoirs (constructed during 1990-2019), and 20 dried-up reservoirs (extinct during 1990-2019). The reservoir types in TB are mainly plain reservoirs with an altitude of less than $1500 \mathrm{~m}$ and an area of less than $10 \mathrm{~km}^{2}$. These types account for about $88 \%$ of the total number of reservoirs. The new reservoirs are mainly distributed in mountainous areas with an elevation of more than $2000 \mathrm{~m}$ and an area of less than $10 \mathrm{~km}^{2}$, while the extinct reservoirs are mainly distributed in plains areas with an elevation of less than $1500 \mathrm{~m}$ and an area of less than $1 \mathrm{~km}^{2}$.

The surface area of TB reservoirs increased significantly from 1990 to $2019(p<0.05)$ at a rate of $12.45 \mathrm{~km}^{2} / \mathrm{y}$. The surface area of 129 reservoirs showed an increasing trend, while 13 reservoirs showed a decreasing trend. The increase in reservoir surface area in the basin has an important relationship with local water resources regulation policy and the temperature increases.

The evaporation rate of reservoirs in TB showed an increasing trend during the study period, with an increasing rate of $0.004 \mathrm{~mm} / \mathrm{d} / \mathrm{a}$. The evaporation rate of 140 reservoirs showed an increasing trend, while 2 reservoirs showed a decreasing trend. SSR and VPD are the main external factors affecting the evaporation rate of the reservoirs, whereas the altitude and area of the reservoirs are the important internal factors affecting the evaporation rate.

Due to the significant increase in reservoir area $(p<0.05)$ and evaporation rate, the evaporation losses of reservoirs in TB showed an increasing trend from 1990 to 2019. The average evaporation volume was $5.25 \times 10^{8} \mathrm{~m}^{3}$, and the maximum evaporation losses of about $6.61 \times 10^{8} \mathrm{~m}^{3}$ occurred in 2017 . This represents 1.34 times the domestic water consumption and 0.84 times the ecological water consumption in the same year.

The results are helpful for gaining a better understanding of trends variation in reservoir surface area, evaporation rates, the relationship between these trends and related variables in arid and semi-arid areas. The results may also provide support for general water resources planning and management in water-scarce areas.

Author Contributions: All authors made significant contributions to this study. Conceptualization, Y.-N.C.; methodology, Q.-Q.X.; software, Q.-Q.X.; writing-original draft preparation, Q.-Q.X.; validation, X.-Q.Z.; formal analysis, J.-L.D. and G.-H.L.; writing-review and editing, Q.-Q.X.; project administration, Y.-N.C.; funding acquisition, Y.-N.C. All authors have read and agreed to the published version of the manuscript.

Funding: This research was funded by the National Natural Science Foundation of China (Grant No. 52161145102) and the Natural Science Foundation of Xinjiang (Grant No. 2021D01D01), also the Strategic Priority Research Program of Chinese Academy of Sciences, (Grant No. XDA20100303).

Institutional Review Board Statement: Not applicable.

Informed Consent Statement: Not applicable.

Data Availability Statement: The data presented in this study are available on request from the corresponding author.

Conflicts of Interest: The authors declare no conflict of interest.

\section{References}

1. Konapala, G.; Mishra, A.K.; Wada, Y.; Mann, M.E. Climate change will affect global water availability through compounding changes in seasonal precipitation and evaporation. Nat. Commun. 2020, 11, 1-10. [CrossRef] [PubMed]

2. Zhao, G.; Gao, H. Automatic Correction of Contaminated Images for Assessment of Reservoir Surface Area Dynamics. Geophys. Res. Lett. 2018, 45, 6092-6099. [CrossRef] [PubMed] 
3. Zhang, H.; Gorelick, S.M.; Zimba, P.V.; Zhang, X.D. A remote sensing method for estimating regional reservoir area and evaporative loss. J. Hydrol. 2017, 555, 213-227. [CrossRef]

4. Bozorgi, A.; Bozorg-Haddad, O.; Sima, S.; Loaiciga, H.A. Comparison of methods for estimating loss from water storage by evaporation and impacts on reservoir management. Water Environ. J. 2021, 35, 218-228. [CrossRef]

5. Mady, B.; Lehmann, P.; Gorelick, S.M.; Or, D. Distribution of small seasonal reservoirs in semi-arid regions and associated evaporative losses. Environ. Res. Commun. 2020, 2, 061002. [CrossRef]

6. Zhao, G.; Gao, H.L. Estimating reservoir evaporation losses for the United States: Fusing remote sensing and modeling approaches Remote Sens. Environ. 2019, 226, 109-124. [CrossRef]

7. Tian, W.; Liu, X.M.; Wang, K.W.; Bai, P.; Liu, C.M. Estimation of reservoir evaporation losses for China. J. Hydrol. 2021, 596, 126142. [CrossRef]

8. Huang, C.; Chen, Y.; Zhang, S.Q.; Wu, J.P. Detecting, Extracting, and Monitoring Surface Water From Space Using Optical Sensors: A Review. Rev. Geophys. 2018, 56, 333-360. [CrossRef]

9. Gao, H.L. Satellite remote sensing of large lakes and reservoirs: From elevation and area to storage. Wires Water 2015, 2, 147-157. [CrossRef]

10. Deng, Y.; Jiang, W.G.; Tang, Z.H.; Ling, Z.Y.; Wu, Z.F. Long-Term Changes of Open-Surface Water Bodies in the Yangtze River Basin Based on the Google Earth Engine Cloud Platform. Remote Sens. 2019, 11, 2213. [CrossRef]

11. Wang, Y.B.; Ma, J.; Xiao, X.M.; Wang, X.X.; Dai, S.Q.; Zhao, B. Long-Term Dynamic of Poyang Lake Surface Water: A Mapping Work Based on the Google Earth Engine Cloud Platform. Remote Sens. 2019, 11, 313. [CrossRef]

12. Xia, H.M.; Zhao, J.Y.; Qin, Y.; Yang, J.; Cui, Y.P.; Song, H.Q.; Meng, Q.M. Changes in Water Surface Area during $1989-2017$ in the Huai River Basin using Landsat Data and Google Earth Engine. Remote Sens. 2019, 11, 1824. [CrossRef]

13. Chen, J.H.; Kang, T.T.; Yang, S.; Bu, J.Y.; Cao, K.X.; Gao, Y.C. Open-Surface Water Bodies Dynamics Analysis in the Tarim River Basin (North-Western China), Based on Google Earth Engine Cloud Platform. Water 2020, 12, 2822. [CrossRef]

14. Penman, H.L. Natural evaporation from open water, bare soil and grass. Proc. R. Soc. London Ser. A 1948, 193, 120-145. [CrossRef]

15. Edinger, J.; Duttweiler, D.; Geyer, J. The Response of Water Temperature to Meteorological Conditions. Water Resour Res. 1968, 4, 1137-1143. [CrossRef]

16. Debruin, H.A.R. Temperature and energy-balance of a water reservoir determined from standard weather data of a land station. $J$. Hydrol. 1982, 59, 261-274. [CrossRef]

17. Mohseni, O.; Stefan, H.G. Stream temperature air temperature relationship: A physical interpretation. J. Hydrol. 1999, 218, 128-141. [CrossRef]

18. McJannet, D.L.; Webster, I.T.; Cook, F.J. An area-dependent wind function for estimating open water evaporation using land-based meteorological data. Environ. Modell Softw. 2012, 31, 76-83. [CrossRef]

19. McMahon, T.A.; Peel, M.C.; Lowe, L.; Srikanthan, R.; McVicar, T.R. Estimating actual, potential, reference crop and pan evaporation using standard meteorological data: A pragmatic synthesis. Hydrol. Earth Syst. Sci. 2013, 17, 1331-1363. [CrossRef]

20. Shi, K.B.; Chen, L.L. Water Saving in the Plain Reservoirs in the Inland Arid Region and Prevention of Salinization in Surrounding Soil; China Water Conservancy Hydropower: Beijing, China, 2016; pp. 1-5.

21. Han, K.W.; Shi, K.B.; Yan, X.J.; Cheng, Y.Y. Water Savings Efficiency of Counterweighted Spheres Covering a Plain Reservoir in an Arid Area. Water Resour. Manag. 2019, 33, 1867-1880. [CrossRef]

22. Wu, S. Estimation of evaporation from Shangyou Reservoir in Aksu Basin. Xinjiag Geogr. 1984, 7, 19-23. [CrossRef]

23. Jiang, H.; He, X.; Liu, B.; Zhou, Y. Study on evaporation rules of plain reservoir in Aksu river basin under background of climate change. J. Water Res. Water Eng. 2014, 25, 81-84. [CrossRef]

24. Chen, H.; Yang, T.; Hu, G.; Wang, S. Study on evaporation change of reservoirs in Yarkant River Basin under climate change. Yangtze River 2016, 47, 31-34. [CrossRef]

25. Zhang, J.; Yuan, Y. A tentative discussion on the impact of climate on surface water resources in Xinjiang. J. Nat. Resour. 2002, $17,28-34$

26. Yu, G.A.; Disse, M.; Huang, H.Q.; Yu, Y.; Li, Z.W. River network evolution and fluvial process responses to human activity in a hyper-arid environment-Case of the Tarim River in Northwest China. Catena 2016, 147, 96-109. [CrossRef]

27. You, P.D. Surface water resources and runoff composition in the Tarim River Basin. Arid Land Geogr. 1995, 18, 29-35. (In Chinese) [CrossRef]

28. Deng, X.Y.; Song, C.Q.; Liu, K.; Ke, L.H.; Zhang, W.S.; Ma, R.H.; Wu, Q.H. Remote sensing estimation of catchment-scale reservoir water impoundment in the upper Yellow River and implications for river discharge alteration. J. Hydrol. 2020, 585, 124791. [CrossRef]

29. Kennedy, R.E.; Yang, Z.G.; Cohen, W.B. Detecting trends in forest disturbance and recovery using yearly Landsat time series: 1. LandTrendr-Temporal segmentation algorithms. Remote Sens. Environ. 2010, 114, 2897-2910. [CrossRef]

30. Zhu, Z.; Woodcock, C.E. Automated cloud, cloud shadow, and snow detection in multitemporal Landsat data: An algorithm designed specifically for monitoring land cover change. Remote Sens Environ. 2014, 152, 217-234. [CrossRef]

31. Yan, Y.B.; Mao, K.B.; Shi, J.C.; Piao, S.L.; Shen, X.Y.; Dozier, J.; Bao, Q. Driving forces of land surface temperature anomalous changes in North America in 2002-2018. Sci. Rep. 2020, 10, 1-13. [CrossRef]

32. Zhou, Y.; Dong, J.; Xiao, X.; Liu, R.; Zou, Z.; Zhao, G.; Ge, Q. Continuous monitoring of lake dynamics on the Mongolian Plateau using all available Landsat imagery and Google Earth Engine. Sci. Total Environ. 2019, 689, 366-380. [CrossRef] [PubMed] 
33. Huang, W.; Duan, W.; Nover, D.; Sahu, N.; Chen, Y. An integrated assessment of surface water dynamics in the Irtysh River Basin during 1990-2019 and exploratory factor analyses. J. Hydrol. 2021, 593, 125905. [CrossRef]

34. Sen, P. Estimates of the Regression Coefficient Based on Kendall's Tau. Publ. Am. Stat. Assoc. 1968, 63, 1379-1389. [CrossRef]

35. Mann, H.B. Non-parametric tests against trend. Econometrica 1945, 13, 245-259. [CrossRef]

36. Kendall, M.; Gibbons, J. Rank Correlation Method. Br. J. Psychol. 1990, 25, 86-91. [CrossRef]

37. Ward, P.; de Ruiter, M.; Mård, J.; Schröter, K.; Van Loon, A.; Veldkamp, T.I.E.; Wens, M. The need to integrate flood and drought disaster risk reduction strategies. Water Secur. 2020, 11, 100070. [CrossRef]

38. Li, J.; Liu, Y.; Wu, T.; Peng, Z. 70 years of dam construction in Xinjiang. J. China Inst. Water Resour. Hydropower Res. 2020, 18, 322-330.

39. Li, J.; Liu, J.; Xie, L. Efficient utilization of water resources and layout of major water conservancy projects in Southern Xinjiang. Water Resour. Plan. Des. 2020, 6, 78-85. [CrossRef]

40. Li, J.; Liu, Y.; Liu, S.; Peng, Z.; Wu, T. Main problems and countermeasures of reservoir dam construction in Xinjiang in the new period. Arid Land Geogr. 2020, 43, 1409-1416. [CrossRef]

41. Xie, X.; Shi, K. Analysis of plain reservoir seepage and downstream soil salinization in arid area. J. Water Resour. Water Eng. 2014, 25, 180-183. [CrossRef]

42. Mohammed, R.; Scholz, M. Adaptation Strategy to Mitigate the Impact of Climate Change on Water Resources in Arid and Semi-Arid Regions: A Case Study. Water Resour. Manag. 2000, 31, 3557-3573. [CrossRef]

43. Li, Y.; Deng, M. Spatiotemporal variations of agricultural water footprint and its economic benefits in Xinjiang, northwestern China. Sci. Rep. 2021, 11, 1-12. [CrossRef] [PubMed]

44. Chen, Y.; Wubuli, W.; Abula, A.; Cheng, Y.; Chen, Y.; Hao, X.; Wang, Y. Monitoring and analysis of ecological benefits of water conveyance in the lower reaches of Tarim River in recent 20 years. Arid Land Geogr. 2021, 44, 605-611. [CrossRef]

45. Ahmad Danboos, O.J.; El-Shafie, A. Effect of Evaporation on the Haditha Reservoir on the Euphrates River in Iraq and Recommendations for Reducing Evaporation Losses. Int. J. Appl. Eng. Res. 2018, 13, 929-941.

46. Han, K.; Shi, K.; Yan, X. Evaporation loss and energy balance of agricultural reservoirs covered with counterweighted spheres in arid region. Agric. Water Manag. 2020, 238, 106227. [CrossRef] 